\title{
GEOGRAPHIES OF SMART URBAN POWER
}

Gareth Powells, School of Geography, Politics and Sociology, Newcastle University

Harriet Bulkeley, Department of Geography, Durham University

Anthony McLean, Department of Town and Regional Planning, Sheffield University

\section{INTRODUCTION}

The language and artefacts of smart grids are increasingly becoming part of the landscape of urban electricity provision. These range from state mandated roll-outs of smart meters to neighbourhood and cityscale innovation projects designed to test the means through which information technologies and new forms of storage, generation and demand management can be integrated in contemporary cities. Yet, despite their significant political, economic and social consequences, research on smart grids to date has focused on their technical components. There has been limited discussion of the social and geographical dimensions of what we argue are in many ways urban processes. We argue that it is through the coming together of urban and national, private and public, social and technical as well as real and imagined geographies in multi-scalar assemblage processes that smart urban energy projects are developed and come to have consequences for communities. In this chapter we examine these processes by drawing on case studies from the UK and USA through which we highlight the different outcomes being created in each context as well as their common elements.

In understanding the city through its relation to energy and infrastructure we draw on the assemblage thinking of writers such as Blok (2012) and McFarlane (2011). We suggest that smart urbanism, with which this volume is concerned, can be understood as a relational process of assemblage in which the found objects of the urban fabric - power cables, gas pipes, buildings, roads and so on - are re-purposed around a new governmental rationales. These are combined with the inserted materialities of meters, data loggers, control room dashboards and screens to create newly alert cities which produce and use energy in markedly 
different ways to what had been normal in the second half of the twentieth century. This process of assemblage is not a simple one however, nor is it one in which all relations are equal. Instead, we show in the chapter that these are processes which seek to establish the conditions for the cultivation of certain dispositions and new socio-technical means for 'conducting the conduct' of the self, family members and in some cases entire communities (Foucault, 1982; Crampton, 2007a online). This is a key aspect of smart grids as entities being actively assembled through urban politics; the sense in which they are socio-technical (both material and discursive) apparatus that seek to alter, "the nature of the connection that can exist between ... heterogeneous elements" (Foucault 1977, cited in Crampton 2007b, online). Furthermore, they represent an urban response to several threats to the current system of energy provision. Foucault argued that this is a common feature of the despositif, the 'thoroughly heterogeneous ensemble' of governmental apparatus; "[the dispositive] has as its major function at a given historical moment that of responding to an urgent need" (emphasis in the original, Foucault 1977, cited in Crampton 2007b online). The perceived urgent need in this context comes from the emerging crisis of the grid through what is widely referred to as the 'energy trilemma'; the need to modernise the grid to provide cities with affordable, secure and low carbon energy.

We argue that the imposition of smart grids on cities and the cultivation of variously socio-technically enabled smart dispositions in citizens creates new lines and of urban politics which in some instances can be overcome through the configuration of new relations as seen in the air source heat pump case study in Section 3.1. In other contexts however urban inequalities risk being intensified. By focussing attention and resources on the priorities of those most able to influence alignment of relations in the relational city - those building the smart city - the co-production of the urban energy assemblages is pushing the concerns of others yet further from the foreground. In developing this argument we show in Section 3.2's discussion of the Pecan Street Project in Austin, Texas how smart energy projects can intensify the socialisation of various risks and the privatisation of rewards which has been so powerfully shown to be a feature of contemporary capitalism (Harvey 2001: 353). 
Using two case studies we suggest that the urban figures as a frontier for the development of and experimentation with smart grids understood as socio-material assemblages gathering in urban contexts around discourses of sustainability, optimisation and security. We argue that smart grids are being operationalised in urban contexts through a set of neo-liberal apparatus and techniques by a diversity of actors. While these socio-material configurations exceed the urban in multiple ways, the development of smart grids is intimately connected to cities as sites of intervention for transformations in the ownership, logics and fabrics of power networks.

In making this argument we develop two claims about the development and deployment of smart grids and suggest that their social and political consequences could be quite profoundly different from existing systems of power supply and use, the histories of which we set out in the first part of the chapter. Firstly we suggest that smart grids are being made possible by a governmental double-logic in that while some state institutions are rolling further back from privatised energy provision through other institutions and apparatus the state can be seen to be rolling-forward. In doing so state institutions are playing new roles in these arrangements and this, we argue, has consequences for the urban as municipal authorities begin to coproduce urban energy networks in new ways. This requires us to move beyond the binary in which economies are either neo-liberal or state-managed to consider new roles and responsibilities for state institutions in smart urban assemblages.

Secondly, we argue that urban smart grids emerge from a tension between the political economy of networked places and the regulated territorial spatiality of the pre-existing energy economy. We refer here on the one hand to urban political economies in which local power geometries have shaped the fabric and function of cities and as a result of which communities are variously affecting and being affected by the emergence of smart urban projects. On the other hand however these place-based processes occur alongside regional and national energy markets and must connect with structures and flows that exceed the urban in many ways. We are suggesting that the work done to articulate these otherwise disconnected processes is an important feature of smart urban power projects.

\subsection{URBAN AS SMART ENERGY FRONTIER}


Interpretations of what constitutes a smart power network vary considerably, but in general 'smart grid' usually refers to schemes introducing information and communication technologies (ICTs) and use of data into energy networks in order to overcome perceived problems. Most often these are connected to some combination of a powerful drive (whether political, commercial or environmental) to shift away from fossil fuel based energy services to renewables while at the same needing to reduce or defer the very large investments in network and generating assets required to maintain security of supply. The sense in which a response is needed, and now, comes both from the urgency of several calls to move away from fossil fuels as well as the dilemma facing network managers. The expected switch to renewables has been anything but a switch, indeed it as thus far been more of an addition meaning that the power system must both remain able to work as it has in recent decades by energising cities with power transmitted from remote power stations while also facilitating the steady emergence of wind and solar generation in the city. The urban arena represents a particular challenge in this regard, and one to which smart has emerged as a 'solution'.

Beyond the hype about the potential of smart grids and their future significance, "actually existing" smart grids are usually only visible in specific demonstration projects and interventions. In 2013 there were estimated to be more than 200 smart grid projects in operation around the world (Lewis 2013), and by 2014 the EU had recorded a catalogue of 459 in the EU alone. The majority of smart grid projects at an advanced stage are being developed in urban areas across Western Europe, North America and Australia. That experimental energy projects are taking place in cities is not new. Electricity grids originally emerged as privately developed and owned entities in cities, with their local monopoly protected by the presence of considerable upfront capital costs and a relative abundance of un-wired spaces rather than regulation but taken together these factors meant that territorial competition was uncommon. Indeed, by 1918, such was the spread of demand and the multiple forms of supply for electrical power that in London alone there were seventy authorities, fifty different types of systems, ten different frequencies and twenty four different voltages (Butler, 2001) all serving the growing metropolis. A growing social and political call for universal provision however led to various rounds of national institutionalisation, regulation and outright ownership changes which led to the early and essential urban geographies of electricity provision becoming relatively invisible if not largely forgotten. This matters in that it leads us to reconsider what we encounter in smart 
urban energy projects as a return to the city as a test-bed for (re-)electrification rather than an entirely novel process. Most centrally we must once again regard this new phase of power provision as a local and geographically variegated phenomena just as was witnessed in London and other cities in the $19^{\text {th }}$ and early $20^{\text {th }}$ centuries. We must become attuned to the outcomes of this process for those on the 'receiving end' (Massey, 1993) of smart grid experiments; with particular streets and communities winning and losing out through the project rather than national plan based approach to infrastructure provision.

Furthermore, historically several factors have contributed to the removal of electricity provision from the urban geographic imagination in the UK and US. These have been both political and technical. In the interwar period in the UK for example the Electric Power Supply Committee recommended the appointment of electricity commissions that would divide the country into district boards which would take over power generation and distribution in their area (Biscoe, 2014). By 1926 The Electricity Act sought to integrate the British electricity supply industry by establishing a $132 \mathrm{KV}$ AC synchronous grid under the newly created Central Electricity Board (Butler, 2001). Doing so required the use and eventual codification of alternating current (AC) generation which was able to use transformers to manipulate voltage at will so that networks could cover much greater distances, in line with and able to serve the national geography of energy governance. Through this socio-technical accomplishment these networks became the robust and long lasting materialities of a national geography of power production and consumption over the course of the mid- and late-twentieth century. This came with a large-few to small-many topology of production and consumption which enabled growing and densely populated cities to be energised by distant power stations (Patterson, 2013), leaving their populations largely unaware of the electrical metabolism of their everyday lives. As the post-war period progressed across Europe, North America, Australia and parts of Asia, Africa and Latin America, power delivery become firmly established as a feature of national status and a symbolic projection of modernity. This was accompanied by a supply-side logic of expand and upgrade which "encouraged the development of large-scale, centralized infrastructure systems of extensive physical networks drawing on increasingly distant natural resources" (Guy et al. 2001: 5.), amplifying the distanciated relation between power and urban communities. In many ways the re-introduction of energy generation in the city and the accompanying re-configuration of the grid is reversing this process with the 
effect that urban communities are once again being confronted with the materialities and constraints of power supply.

We argue that in the contemporary context a new phase of grid-management is emerging (Ofgem 2011) which seeks to intensify some of the characteristics of marketised infrastructures that became widespread in the late twentieth century. In important ways however it goes beyond the single, simple and spatially onedimensional narrative of nationally bound markets for energy. Brown has argued that, "this century will see the localisation of energy production" (Brown, 2011: 206)), which we see as a process unfolding alongside Graham and Marvin's argument about the emergence of an, "entirely new infrastructural landscape that radically challenges established assumptions that have underpinned the relations between integrated networks and cities" (Graham and Marvin 2001: 139). Taken together these two processes of localisation and utility integration through ICT are renewing and deepening the relation between cities and energy networks through and as a result of smart urban power projects. Evidence of this can be found in the concentration of European smart grid funding allocated to a small number of urban 'hot spots' where collaborations between DNOs, TSOs and universities have been most effective in forming smart grid projects. The places most likely to host smart grid projects are, according to the EU's 2014 review of all smart grid research in Europe, in, "the vicinity of major organizations involved in research, innovation, or managing the national or regional transmission networks (major cities as London, Paris, Brussels, Barcelona, Roma or university centers as Bilbao, Grenoble, Arnhem, Karlsruhe, Copenhagen)" (Covrig, Ardelean et al. 2014: 37). These criteria, of course, mean that urban sites are particularly likely to be arenas for smart grid research.

These criteria point to the ways in which the urban is essential to smart power. While the logic of universal provision of electricity embedded in national energy projects could effectively bypass geographical difference, the logic of smart grids is both dependent upon and constitutive of locally differentiated forms of power production and use. As urban geographies become key to the development of new forms of power 
provision and changing patterns of electricity use, previously invisible relations between the urban and the network come to matter in material and political terms.

A future based much more heavily on distributed generation dispersed throughout the urban fabric of cities poses serious technical and social challenges both for cities and the grid. Without viable electrical storage technology ${ }^{1}$, 'smart' demand will need to be supply-synced via context-specific technical and cultural devices. These include in-home displays and market mechanisms through which the ways in which people demand energy is reconfigured around the new smart grid assemblages. This is in stark contrast to both the Fordist - Keynesian model of universal power provision of the post-wart period but also is markedly different to the period of liberalisation and unrestrained consumption that followed. In both these previous contexts the supply processes was demand-led through the use of flexible, predominantly fossil fuelled, power generators which could be ramped up or down to match demand the demand of cities without ever imposing constraints on energy use. In the smart grid, flexibility must be induced into energy demand to compensate for the increasing inflexibility of renewable, local and non-storable supply.

Smart grid assemblages promise to, "improve both the physical and economic operation of the electricity system by making it more sustainable and robust, more efficient by reducing losses while at the same time offering economic advantages for all stakeholders" (Verbong, Beemsterboer et al. 2013: 117) Furthermore, in bringing about this transformation in energy provision and use, smart grids also resonate with attempts elsewhere in the governance of cities to leverage, "networked infrastructures to improve economic and political efficiency and enable social, cultural and urban development" (Hollands 2008: 307). Delivering on these promises remains challenging however and in the following case studies we draw out some of the political and social consequences for cities and their citizens.

\section{CAse Studies}

\footnotetext{
1 There are currently no commercially available, large scale electricity storage technologies that can store electrical energy at even neighbourhood scale.
} 
Before proceeding to develop our two claims regarding the public-private character of smart grids and the tensions between territorial and topological processes therein we first introduce the two case studies on which the chapter draws.

\subsection{UK SMART GRIDS- The CUSTOMER LED NETWORK REVOLUTION}

The CLNR project is a partnership between Durham and Newcastle Universities, a major UK gas and electricity supplier (British Gas) and North East England and Yorkshire's low voltage distribution network operator (Northern Powergrid). The project is funded through the UK's Low Carbon Network Fund, a centrally managed fund established by the national energy regulator Ofgem to provide incentives and directly fund power system innovation. The project features experiments with a range of social, technical and socio-technical innovations on the low voltage network and in customers' homes. These include conventional and 'smart' heat pumps, time of use tariffs, electric vehicle charge points, a range of grid-side electrical energy storage devices (battery storage), photo-voltaic panels and in-home displays in various combinations each studied a discreet 'test-cell'. The project collected consumption data from over 10,000 homes and small organisations, each of whom was invited to take complete an online survey which resulted in 913 valid responses. 186 of the participants also took part in a qualitative research visit which included a semi-structured interview and an energy tour of their home or premises. Drawing on CLNR, we consider the economic and political geographies of spatially and temporally overlapping and interacting processes already active in UK energy systems. We examine the interactions between efforts to cultivate a nation of 'smart' consumers in UK electricity supply markets and the development of new forms of locally specific urban 'network flexibility'.

[INSERT IMAGE 1: The low voltage smart grid as imagined in the UK context]

\subsection{Austin and The Pecan Street Project}

The Pecan Street Project (PSP) in Austin, Texas, is a non-profit public-private partnership that hopes to provide a 'proving ground' for technologies and ideas that can be used to advocate, "changing the rules, changing the market, providing new incentives [and] educating consumers" (Interview, Environmental Defence Fund representative). It is focused on a volunteer group of 1,000 residents and seventy five 
commercial businesses in the city's Mueller district, a planned urban development on a former airport undergoing redevelopment, and operates as a 501(c)3 venture - a non-profit organisation which can attract tax deductible charitable donations. Although the University of Texas provided an initial $\$ 50,000$ to kickstart the project major work did not begin until the US Department of Energy provided a \$10.4 million grant in November $2009^{2}$. This grant money has been matched with $\$ 14$ million from external partner organisations, mainly private companies, providing funding for research for five years.

In the PSP case study presented here we draw on interviews with a range of actors involved in the project including managers, directors, business owners and administrators from private, public and voluntary sectors. This is in contrast to the CLNR case study from the UK which draws on interviews with householders.

[INSERT IMAGE 2: Solar SunFlowers - a public art installation on the edge of Austin's Mueller district that helps power a nearby retail park]

Drawing on these case studies we develop two arguments about the emergence of smart grids.

\section{PUBliC-PRIVATE URBAN SMART GRID ASSEMBLAGES}

The first of our two claims is that the development of smart grids in urban contexts comes with a double logic. In some senses these initiatives can be interpreted as a further intensification of the privatisation of energy provision and marketization of energy use, through which energy use can be more accurately measured, traded and customers made more flexible and fluid than at any time in the history of networked power provision. While the marketization of energy systems was accompanied by a rolling-back of the state the creation of these newly sensory networks is being done, in many cases, through public-private innovation projects in which local and national state institutions are in some senses rolling-forward. State institutions are acting to structure and subsidise projects through mechanisms such as the UK's Low Carbon Network Fund and the US government's 2009 American Recovery and Reinvestment Act to fund energy

\footnotetext{
${ }^{2}$ (The DoE itself was awarded $\$ 36.7$ billion under the 2009 American Recovery and Reinvestment Act to develop renewable generation and promote conservation and efficiency schemes across the country).
} 
initiatives, which has led the New York Times to call it the, "biggest energy bill in history" (New York Times, 2009, online). At the same time, state institutions are actively directing interactions within smart energy systems. In the UK for example, a Smart Energy Code has been established as a formal code of conduct that governs the all interactions between parties in smart power system. Meanwhile a licensed and heavily regulated monopoly contractor has been appointed as the Data Control Company which will perform data flow, access and will curate smart meter data on behalf of customers (who remain the owners of the data) and any party seeking to access their energy use data. Smart grid projects can therefore be seen as coproduced hybrids of state and private interest which emerge from partnerships and which have contextspecific social and environmental consequences. This pattern of public-private partnership can be seen in the 2014 review of smart grid projects in the EU in which the 459 projects were found to have a (mean) average of nine partnering organisations per project. Among the parties listed municipalities, public authorities and the government feature in a list of other, private, entities co-experimenting in mostly urban contexts (Covrig, Ardelean et al. 2014).

We suggest that the emergence of new forms of 'smart' energy provision works by drawing together actors, materialities and communities each with their own political and economic geographies into smart grid coalitions, echoing wider public-private partnerships common in the late 1990s and early part of the twenty first century in urban and infrastructure governance. Smart grid coalitions, by loosely bundling concerns regarding environment, social justice, urban competitiveness and commercial risk management together in awkwardly inclusive initiatives, have created a consensual, multi-level and multi-stakeholder mode of intervening simultaneously in the city and in the energy network. These developments can be characterised as representing 'socio-technical fixes' (Hodson and Marvin 2014: 123) and as extensions of the urban entrepreneurialism of the 1990s (Harvey 1989, Wood 1998). Smart grids, we suggest, are one such 'sustainability fix' around which actors and discourses are beginning to establish positions in the urban arena. The effect is that ideas about what it means for the city to be smart are consolidated and made stable through a consensual urban politics of strategic partnerships between elite and or powerful actors such as utilities, universities, housing providers and state institutions. 


\subsection{Public-Private HeAting IN TYNESIDE}

To develop these ideas we draw on a trial of domestic air source heat pumps that was part of the CLNR project. 322 air source heat pumps were installed in homes in the North and North East of England in connection with the CLNR project, most of them clustered together on particular distribution network feeders to enable analysis of their combined effects on the distribution network at urban network scale. An air source heat pump (ASHP) is a device that uses electricity to recover low level ambient heat energy in the air outside a building for use in the building's space or water heating systems. These devices are typically in the range of $300 \%-500 \%$ efficient, meaning that for every unit of electricity they use they produce 3 to 5 units of heat. Drawing on interviews and home energy tours conducted with eighteen participants from the 322 ASHP users involved in the trial we comment here on the co-produced nature of the trial and what it reveals about the relation between national, regional and local energy economies and places.

Finding hundreds of households in which to install heat pumps was the role of the energy supplier on the project British Gas (who, despite their name, are the biggest electricity supplier in Great Britain). British Gas operate across the entirety of Great Britain and the design of the CLNR project mirrored the UK's unbundled market structure in that the supplier was responsible for all customer interactions while the DNO was responsible for all network interventions. The ASHP trial however required a re-bundling and augmentation of these roles as the trial needed a locally clustered group of customers in order to test the combined local effects of widespread electrification of domestic heat services.

In order to recruit locally concentrated customers to the trial a third party partner was required as British Gas's customer base does not follow the urban geography of the network as each household can choose to be supplied by (and thus have a relationship with) any supplier with a license to operate in the UK. In contrast the DNO has continuous feeder wires that were to be equipped with monitors to sense the combined local effects of the ASHPs at substations. A new entrant to the energy provision system was needed to overcome this mis-match between national-market vs local-material geographies. This partner was local social landlord South Tyneside Homes, an arms-length management organisation (ALMO) created by South Tyneside Council to manage, maintain and improve its council homes and estates (South Tyneside Homes 
2014). STC is a non-profit-making company that is $100 \%$ owned by South Tyneside Council, the municipal government. As an ALMO, South Tyneside Homes facilitated access to a housing estate in which all homes were served by the regional DNO and all residents had a relationship with a single housing provider. This became an important relationship that British Gas were able to use to both achieve operational efficiencies but also to manage customer questions, complaints and to provide opportunities for residents to speak to representatives of all CLNR project partner organisations. In doing so, the trial of ASHPs used place-bound relationships created and maintained by municipally owned housing providers to work around and overcome the tensions of the unbundled private energy sector.

A further obstacle was encountered however which highlighted the uneven geographies of infrastructure access. Most of the residents recruited to the trial did not have a home internet connection - with the majority either having no internet access at all or using mobile internet only. This meant that the data from the ASHP and domestic circuit monitors would be unable to flow back to the project's data centre. To overcome this issue British Gas had to take on the responsibility of being an internet service provider to the housing estate, which was both an operational challenge and a novel move for the energy supplier but was essential in order to make this particular smart grid initiative feasible. In so doing, British Gas crossed over from being a competitive energy supplier to become, in this place and time, and public internet provider, providing an illuminating example of the blurring of boundaries, roles and responsibilities that are more typical of smart grid assemblages than exceptional features of this case.

We argue that this exemplifies in many ways that the geographies of smart energy do not tessellate neatly and that the tensions between supplier and DNO spatialities require place based partnerships that exceed the vertically imagined unbundled electricity system. In this way these place-based relationships in which municipal government and its subsidiaries are central actors become valuable to the grid and lead to local state and quasi-state actors being invited to play a vital role in resolving the tensions between the awkwardly configured privatised power system. We argue that we can see here an example of the co-provision of urban energy governance by both public and private sector actors working in consensual ways to resolve tensions 
built into the market structure of the UK's energy system. We now turn to a case study from the US to further develop these points.

\subsection{The Public-Private Smart Grid in TeXas}

"Literally, policemen are laid off if this utility doesn't make a profit" (Interview, Environmental Defense Fund).

The Pecan Street Project reveals that although there are very different drivers in the Texan case, they nonethe-less point to the important role played by municipalities in shaping the future of urban energy provision. PSP's status as independent non-profit allows it to act as an arms-length organisation outside of the control of any single actor, although its founding partners play a key role in directing research. Six organisations have seats on the board - The University of Texas, the City of Austin, the city-owned utility Austin Energy, the Chamber of Commerce, the Environmental Defence Fund and the Austin Technology Incubator (itself a business investment arm of the university). Below this board are a range of external companies who have provided funds and seconded staff to the project.

The high-tech history of Austin and the city's past experience with public-private partnerships has created a group of urban elites who have both accumulated experience of and been acculturated into the doings and sayings (Shove, Pantzar et al. 2012) of public - private collaboration across sectors. In 1982 several US computer and semiconductor manufacturers formed the Microelectronics and Computer Technology Corporation (MCC) in Austin - the first computer industry research and development consortium in the US. This was followed by Sematech in 1986. Both consortia were non-profit research and development organisations and worked in partnership with a diverse range of actors, including state and federal government officials, research institutions, business representatives and manufacturers. For Austin these consortia were very successful (Smilor, Gibson et al. 1989) in fostering the conditions for a similar entity to emerge in the form of the Pecan Street smart grid project.

Although the PSP is a public-private partnership with the city-owned Austin Energy working with a number of private organisations many participants interviewed believe any smart grid should be private sector-led rather than driven by the state. Distributed generation technologies and demand management systems for 
sale in an open market were preferred to a mandated state roll-out of smart technologies. Interviewees believed that the change to a new grid should be facilitated by purchases made by willing customers in a competitive market setting. Yet, interviewees in Austin also recognised that the deployment of new generation technologies and demand response software could reduce gross demand and therefore the utility's revenue, on which the city relies for the provision of a range of otherwise non-energy related services, as illustrated by the quotation above. These contingencies between energy, the grid and public services are locally specific, no doubt, but they are part of a wider pattern in smart grid innovation initiatives in which risks and investments are shared by state and commercial entities. Central to this is a common discourse about the future of the grid and a shared rationale that partakes of commercial, environmental and governmental logics which, we argue, is a feature of the wider smart grid assemblages. We suggest that this means that in cities, new constellations of actors will increasingly look for ways to re-figure risks and rewards as part of the attempts to connect smart urban futures to the grid. However, while the purpose of smart energy technologies is hybrid in nature - drawing on these multiple rationales - the Austin case reveals that the techniques and apparatus through which grids are becoming smarter are in many ways neoliberal. They remain based on consumer choice-making and responsibility as the engine for the transformation of energy provision. In so doing contribute to the normalisation of the view of the urban citizen as an economic agent, as is recognised by Strengers in her depiction of 'resource man' (Strengers 2013) as the protagonist of smart grid narratives. In this way they contribute to the erosion of other possible narratives of smart urbanism including those of citizenship, sharing and solidarity.

This can be seen in the imagined future of the urban fabric as host to a web of micro- and decentralised power plants in constant state of transaction. In Austin, researchers are experimenting with a system in which the energy utility is transformed into a socio-technical platform that facilitates peer-to-peer transactions between individual residents generating and consuming locally produced and only locally circulating energy. At thousands of small distributed generation nodes the utility aims to embed metering apparatus to record transactions as well as energy flows in order artificially construct and record the sale of discreet units of exchange as a means of disentangling an otherwise seamless state of electrical flow and potential. In so doing, the PSP is creating space and socio-technical apparatus for a new energy market to 
emerge and facilitating individual transactions between urban residents. The utility will operate and maintain the underlying electrical infrastructure - transmission lines, a base generation capacity and an automated software management service - and the new system will charge a subscription fee to those wanting to operate within the decentralised marketplace. In this system rather than being an energy user each individual home and business is re-constituted as a 'pro-sumer' (producer and consumer). One interviewee described this 'brokerage' system:

"I, as a utility operator, am going to be a sophisticated platform that provides energy one way when you need it, takes the energy the other way when you don't need it, monitors the storage and the plug-in and brokers all this distributed onsite generation storage and consumption. I become the infrastructure, and I take a little fee for transactions for monitoring all this" (Interview, former Austin Energy executive, May 2012).

The aim is to provide all parties with "choices and control as opposed to giving the utility or government control" (interview, Environmental Defence Fund representative, May 2012). Thousands of pro-sumers will engage in constant micro-transactions with peers across the city and what was once a highly centralised, publically-managed grid network is imagined to become a dispersed, variegated and dynamic marketplace yet still reliant on a large technical network owned and operated by the city. On top of this platform, third parties could develop their own software, hardware and services to sell to residents, while Austin Energy itself will provide a back-up guarantee of service to maintain a basic level of universality to the city. Through this mechanism, the initiative adopts perhaps the most emblematic feature of public-private infrastructure provision and capital expansion; the socialisation of risk and the privatisation of reward.

\section{ACTUAlly EXISTING GEOGRAPHIES OF SMART URBAN POWER}

The second claim we make about smart grids as features of real contemporary cities and those of the near future is that the conjunction of the urban placement of smart grids together with their hybrid political character which we have discussed above means that such projects need to be analysed in relation to their particular manifestations in specific places. Informed by Harvey's insight that the urban entrepreneurialism he observed in the late 1980's was driven by a political economy of place rather than territory (Harvey 
1989b) we argue that actually existing smart grids are produced by a tension between the political economy of networked places and the regulated, territorial patchwork of the pre-existing energy economy from which projects are emerging. By networked place we mean both networks in the technical sense - the routes and limits of wires and ICT network coverage - as well as an emphasis on the public-private partnerships - the governance networks - already in place in cities and towns in the vanguard of smart energy experimentation.

In addition to place-based urban interventions, territorially bounded smart networks are also being fashioned through the roll-out of one specific device - the smart meter. A number of smart meter-only projects have already been initiated globally, including in Australia, the UK, where the roll-out involves installing fifty million gas and electricity meters in twenty seven million homes by 2020 , and the United States where as part of the Recovery Act over fifteen million smart meters have been installed nationally in each of the last 4 quarters (Q3 2013 to , Q3 2014) (US Department of Energy 2014). These meters are positioned as necessary pre-conditions for the creation of smart urban spaces in which consumers are equipped with cultural and technical devices (market structures and metering) which make it possible for energy use and provision to take on new qualities. In more explicitly Foucauldian terms, we are arguing that these devices establish the conditions for new forms of energy use mentalities and forms of control to be cultivated.

We find it troubling that the socio-technical imaginary of smart energy seems to be a placeless future in which the operating environment is smoothed through the erasure of local, mechanical, physical or contractual boundaries between actors, places and devices. Such devices, - what Deleuze and Guattari (Deleuze and Guattari 2004) might call 'striations', act as socio-technical markers which divide spaces up, reduce openness and impede flexibility and are notable through their absence from imagined smart futures. Indeed, Hubert observes that, "although they never mention it, the grid must stand as both the emblem and diagram of striated space." (Hubert (n.d.) online). Our contention here is that it is only ever from this highly striated space that smart energy projects start. From these beginnings they seek to establish a hyperconnected set of inter-infrastructures in cities in which nodes, such as homes or businesses, are always connected to everything and follow common protocols which mean also that anything can be plugged into anything. The imagined results being free-flowing data, instantaneous re-configurability and the avoidance 
of interruption. The reality of actually existing urban smart grid assemblages is, perhaps inevitably, markedly different and we find them to be highly striated, uneven and constrained as a result of interactions between the totalising territoriality of smart metering roll-out and the supply markets and the durable geographies of networks and places. In the remainder of this chapter, we use the case studies of Austin Texas and the North East of England's Customer Led Network Revolution to illustrate these points.

\subsection{MARKET TERRITORIES AND GRID PLACES}

We have argued above that the UK's energy geography comes with in-built tensions as a result of its regionally licensed distribution network monopolies, urban smart grid initiatives the national scale led smart meter roll out. It is in places, often in cities, where these geographies meet, interact and are negotiated. The UK's national smart meter roll-out, aligned with the geography of the energy supply market, seeks to create a 'smart nation', in which locality and geographic specificities are overcome. It will be the responsibility of energy suppliers, active in the retail market, to buy or rent smart meters and distribute them to customers passing on the equipment, admin and installation costs to a greater or lesser extent. In basic terms, the immediate benefits of a smart meter are that they provide accurate consumption feedback to the household and accurate meter readings to the energy company, usually every thirty minutes.

Electrical distribution networks are structured differently. These are hierarchies of transformers housed in substations which bring voltage down from ultra-high voltage national transmission to the 400v low voltage distribution networks in most streets in the UK. As a result, low-voltage network management and community engagement are conducted by distribution network operators at 'network scale', which is most naturally aligned to 'sub-station communities' - clusters of households and businesses determined by the layout of the wires which result from histories of regulation, network governance and engineering decisions. Motivations for smart grid development at the distribution level are, as a result, focused on enabling the anticipated connection of solar photo-voltaic panels, electric vehicles, electrically powered heat pumps and various forms of energy storage as well as finding ways to avoid or defer investment in network reinforcement. The goal of network trials such as the CLNR is to create local network flexibility as an alternative to costly reinforcement, which had previously been the dominant mode of securing network 
reliability. Within this logic, contextually specific commercial risk and cost management can be seen to be working in interaction with governmental, regulatorially enforced commitments to renewables and supply security which exert pressure across the regulated space. What results is a rationale for innovation and experimentation through projects which seek to re-negotiate these tensions in each instance.

The local is important for two reasons; firstly the local nature of DNO-led smart grids is in contrast to the national geography of supplier-led smart metering roll out. Secondly, even locally there is a preference for 'smooth' space, with contiguous customer connections, the absence of boundaries and other 'striations'. The reality is that every house in a street, or every flat in a tower block will have its own supplier relationship, broadband contract, mobile phone contract and may or may not have other contracts with gas, oil or biomass suppliers. In various ways these variegated states of connectivity amplify, attenuate or prevent customers from adopting an active or smart identity in newly configured urban smart grid assemblages. These striations, the lines between customers of different companies and between formal responsibilities and licenses to operate, also dilute the value of customer engagement and in many ways curb the possible contributions of the community to new forms of power provision. Until communities on common feeders begin to act together by choosing to group-purchase from a common supplier to achieve different forms of energy provision which work with and for them or until actors coordinate at the local level on behalf of the others stakeholders citizens will only able to engage with smart urban power in very diluted ways. This type of community scale self-awareness and action is of course a rarity.

\subsection{The New Smart MarketPlace}

We now turn to the US case study to consider the implications of new market configurations in urban smart grids. By choosing to use a marketplace as a decision making and resource allocation engine the Pecan Street Project system introduces new forms of inequality. We interpret this as a form of power geometry in the way that processes of smart urban power touch down differently in different places and impact communities in different ways - with some benefitting from the opportunities associated with being a prosumer and others being 'on the receiving end' (Massey 1993). For some socio-economic groups Austin Energy will be just one provider of energy management services with the development of highly 
individualised and specialised products and contracts to choose from. This is not necessarily a negative aspect of the future smart grid and will be welcomed by many. However, residents with the time and resources will have opportunities and incentives to upgrade their own appliances to improve efficiency, install their own solar panels and wind turbines and then pay Austin Energy to manage their consumption and generation on their behalf. In effect, those able to do so will become players in the market, able to choose which flows to send or receive, which transactions to approve and on which terms to participate in. In contrast, those unable to afford the capital investment required to become owners of the still expensive distributed generation technologies could be forced onto flat-rate pay-as-you-go contracts with new and more constraining conditions about home appliance use, albeit through service offerings badged as 'smart' and 'flexible'. In such situations, those configured by rather than configuring the smart grid will be positioned within flows and transactions orchestrated to enhance the positions held by more powerful actors in the market place. For example they will be reliant on making their rooftops 'available' to those in driving seat of smart urban power:

“...They'd agree to reduced-cost appliance upgrades such as solar water heaters. They'd participate in Austin Energy's demand response program, which might cycle off their air conditioners in fifteen-minute increments on the city's hottest days. They'd agree to limit their peak use of non-essential appliances in favour of off-peak use. They would never be denied power when they need it. But they would agree that using energy at certain times - outside their service plan - would be "pay as you go," just like tossing more garbage than will fit in your city-issued trash can is "pay as you throw"” (Pecan Street Inc, 2010: 16).

As Graham outlined more than a decade ago such infrastructural 'choice' tends to be limited to "certain social and spatial groups within the city. The ability to access competing providers is dependent on wealth, location, skills and how lucrative one is to serve" (Graham 2000: 192). Creating a 'pay as you go' system for those unable to participate in Austin's smart grid will mean that the conditions of possibility for some participants' energy use will be markedly narrower than is currently the case. The potential for an increase in infrastructural splintering and the targeting of specific socio-economic groups was highlighted by one interviewee: 
“...we might actually be on the threshold of a word we used to use in the early days, of 'customerisation'.

We might actually get to the place where this technology enables the utility to say 'these are stay-at-home moms who keep their air conditioner running and run the dishwasher and have the TV running and a couple of other appliances, and we really ought to figure out a way to keep all of them from being on-peak at the same time'. Go to their house, put these controls in place, stop them from quadrupling their peak for a few minutes at a time. But in my house where my wife and I are both gone all day, don't deploy the hardware, ... I would say that it's probably going to be better for us to segment our customers before we try to deploy this crap to every single person” (Interview, Austin Energy executive, May 2012).

This represents an extension of neo-liberal apparatus and techniques into the everyday life of citizens as part of making the public-private smart grid work. While Austin Energy, a state institution, will be rolled back from service provision for urban residents able to be active in the market, it will be simultaneously increasing the scope of their interactions with residents unable to fully become pro-sumers. In effect this is likely to result in hard-controlling their appliance use and introducing dynamic and time-of-use pricing as 'soft' controls on overall energy demand.

\section{CONCLUSIONS}

Through these two case studies we have developed an analysis which points to cities and urban contexts as frontier spaces for smart grids and which draws attention to the emergent geographical politics of actually existing, public-private assemblages beginning to deploy smart urban power. Both case studies offer warnings about the difficulties and various flexibilities (on the parts of consumers as well as those bringing the projects forward) needed to reconcile the tensions inherent in the knotted private apparatus of entrepreneurial urbanism and that of regulated power network management. They also illustrate the uneven power geometries at work which produce smart grids that will be experienced differently by different constituencies despite being driven by consensual multi-stakeholder partnerships unless significant efforts are made to attend to the unevenness that barriers, blockages and inequalities are producing, with clear differences between UK and US experiences. The cases reveal that despite the promise of a smooth space for the development of new products, services, identities and innovations the reality is that the logic of 
smart, at least for the short and medium term, is encountering a highly striated urban environment which limits the purchase that logics of smart grid have in terms of their ability to conjure radical energy transitions. This should be a clue to the immanent qualities of smart urban assemblages, that they are being produced by already existing embedded historical energy and urban geographies rather than being inserted into places from elsewhere, or from 'the top'.

The history of urban power outlined in Section 1 stands a useful reference point and exposes the ways in which urban power provision, smart or otherwise, is always variegated and tied to local economic geographies rather than being rolled out in a uniform manner a across territories. However, smart urban assemblages can in many ways be seen as the adoption by broad coalitions in urban contexts of the apparatus of the twenty first century economy and particularly its emphasis on flexibility and alertness which resonates so closely with the discourses and practices of smart cities being discussed elsewhere in this volume. This is in clear contrast to the dominant mode of infrastructure provision of twentieth century outlined in Section 1.1 in which network management valued and projected material strength and stability rather than socio-technical flexibility and alertness.

Elsewhere in the chapter we have shown that the use of markets, digital devices and dispositions to create pro-sumers able to act and react to the 'state' of the grid is a distinctive change in how and from where reliable urban power is provided. It seeds the growth of many tiny nodes throughout the city which each contribute to secure (and hopefully clean) energy provision rather than having cities reliant on a small number of large, remote nodes of generation and control. This comes hand in hand with a change in how citizens demand power. Following from this, we suggest that research on smart urbanism needs to use or develop analytic resources that can attend to the economic geographies of flexibility as they extend out into the everyday lives of citizens as well as how they force new forms of flexibility in terms of how publicprivate initiatives allocate roles, risks and responsibilities. More particularly, while flexibility has received much attention from Geographers in studies of production and labour (Hudson 1989) we argue that geographies of flexible consumption and leisure have been relatively underutilised and have not yet been fully linked to the alertness and responsiveness that are becoming so central to smart urban assemblages. 
We have suggested a number of ways in which the urban has implications for energy but we now turn to reflect on the consequences of smart urban power for the city. First we suggest that new forms of urban energy are deepening the sense in which the city is co-produced by a complex multiplicity of diverse actors, actants and processes. The partnerships and socio-technical accomplishments of smart grids considerably add to the degree of complexity in public-private arrangements that contribute to the constant reestablishment of the conditions necessary for everyday life in the city; power., heat, telecoms and so on. However, these projects are becoming more central, more essential to the fabric or urban governance and to describe them as mere features of the contemporary city is unsatisfactory. Smart urban projects, among which smart power projects are some of the most significant and impactful, are (financially and geographically) sufficiently large and important that they can be thought of as becoming a dominant style of project-work in the city. While writers in the assemblage urbanism literature have emphasised the, "multiple political projects, modes of governance, practices and outcomes of cities as assemblages (McGuirk and Dowling 2009) we suggest that within this picture of complexity and multiplicity there are some projects, some modes of government that are more central and more definitive of the new urbanism than others. We suggest that smart urbanism, and smart urban power as an important feature thereof, challenges the analytic neutrality of some assemblage thinking because of the sense in which a nervous system is being created as an end in itself, one which spans energy, heat, traffic, air quality and so on. This is a sensory apparatus in which, we acknowledge, there may be no single 'brain', no space or node of ultimate power or knowledge but in which the process of constructing sensory capabilities and connections constitutes more than just one project among may. These are attempts to connect the otherwise feral forces of urban assemblage through a socio-technical but always political process which will continue to induce a power geometry through which winners and losers are created and, in different ways, revealed and obscured. 
Blok A, 2012, "Urban Assemblages: How Actor-Network Theory Changes Urban Studies" Science as Culture, 21: 283-287

Biscoe J, 2014, "History of public supply in the UK", http://www.engineeringtimelines.com/how/electricity/electricity_07.asp (accessed 22/4/2015).

Brown L, 2012, "World on the edge: how to prevent environmental and economic collapse", in The Sustainable Urban Development Reader, Eds S Wheeler, T Beatley (Routledge, London) pp 205 - 214

Butler S, 2001, "UK Electricity Networks: The nature of UK electricity transmission and distribution networks in an intermittent renewable and embedded electricity generation future", Parliamentary Office of Science and Technology, London

Covrig C F, Ardelean M, Vasiljevska J, Mengolini A, Fulli G, Amoiralis E, Jimenez M S, Filiou C, 2014, "Smart Grid Projects Outlook 2014", in Science and Policy Report by the Joint Research Centre (European Commission Luxembourg)

Crampton J, 2007a, "Key term: conduct of conduct", in Foucault Blog, https://foucaultblog.wordpress.com/2007/05/15/key-term-conduct-of-conduct/ (accessed 22/4/2015).

Crampton J, 2007b, "What is the dispositif?", in Foucault Blog, https://foucaultblog.wordpress.com/2007/04/01/what-is-the-dispositif/ (accessed 22/4/2015).

Deleuze G, Guattari F, 2004, A Thousand Plateaus: Capitalism and Schizophrenia, Continuum International Publishing Group Ltd., London

Graham S, 2000, "Constructing premium network spaces: reflections on infrastructure networks and contemporary urban development" International Journal of Urban and Regional Research, 24:183-200

Graham S, Marvin S, 2001, Splintering Urbanism: Networked Infrastructures, Technological Mobilities and the Urban Condition, Routledge, London ; New York

Guy S, Marvin S, Moss T, 2001, Urban infrastructure in transition: networks, buildings, plans (Earthscan Publication)

Foucault M, 1980, "The Confession of the Flesh", in Power/knowledge: Selected Interviews and Other Writings: 1972-1977, Ed G Colin (Pantheon Books)

Foucault M, 1982, "The Subject and Power" Critical Inquiry 8 777-795

Harvey D, 1989 The Condition of Postmodernity: An Enquiry Into the Origins of Cultural Change, Wiley, London

Harvey D, 1989b, "From Managerialism to Entrepreneurialism: The Transformation in Urban Governance in Late Capitalism" Geografiska Annaler. Series B, Human Geography, 71: 3-17

Harvey D, 2001 Spaces of Capital: Towards a Critical Geography, Routledge, London

Hollands R G, 2008, "Will the real smart city please stand up?" City, 12: 303-320

Hodson M, Marvin S, 2014, After Sustainable Cities?, Routledge, London 
Hudson R, 1989, "Labour-market changes and new forms of work in old industrial regions: maybe flexibility for some but not flexible accumulation" Environment and Planning D: Society and Space, 7: 5-30

Lewis P, 2013, "Smart Grid 2013 Global Impact Report", VAASA ETT, San Francisco

Massey D, 1993, "Power-geometry and a progressive sense of place", in Mapping the Futures: Local Cultures, Global Change Eds John Bird, Barry Curtis, Tim Putnam, George Robertson, L Tickner (Routledge, London)

McFarlane C, 2011, "Assemblage and critical urbanism" City, 15: 204-224

McGuirk P, Dowling R, 2009, "Neoliberal privatisation? Remapping the public and the private in Sydney's masterplanned residential estates" Political Geography, 28: 174-185

Ofgem, 2011, "Smart metering - what it means for Britain’s homes", Ofgem, London

Patterson W, 2010,3 Transforming Electricity: The Coming Generation of Change Routledge, London

Shove E, Pantzar M, Watson M, 2012 The dynamics of social practice: everyday life and how it changes (Sage)

Smilor R W, Gibson D V, Kozmetsky G, 1989, "Creating the technopolis: High-technology development in Austin, Texas", Journal of Business Venturing, 4: 49-67

South Tyneside Homes, 2014, "FAQs", http://www.southtynesidehomes.org.uk/article/11365/FAQs , (accessed 22/4/2015).

Strengers Y, 2013 Smart Energy Technologies in Everyday Life (Palgrave Macmillan)

The New York Times, 2009, "An $\$ 80$ Billion Start", http://www.nytimes.com/2009/02/18/opinion/18wed1.html, (accessed 22/4/2015).

US Department of Energy, 2014, Advanced Metering Infrastructure and Customer Systems

While A, Jonas A E G, Gibbs D, 2004, "The environment and the entrepreneurial city: searching for the urban 'sustainability fix' in Manchester and Leeds" International Journal of Urban and Regional Research, 28: $549-569$

Verbong G P J, Beemsterboer S, Sengers F, 2013, "Smart grids or smart users? Involving users in developing a low carbon electricity economy" Energy Policy, 52: 117-125

Wood A, 1998, "Making sense of urban entrepreneurialism" Scottish Geographical Magazine, 114: 120-123 